\title{
A ANTROPOLOGIA PELO DESENHO: EXPERIÊNCIAS VISUAIS E ETNOGRÁFICAS
}

Karina Kuschnir ${ }^{1}$ UFRJ, Rio de Janeiro, Brasil

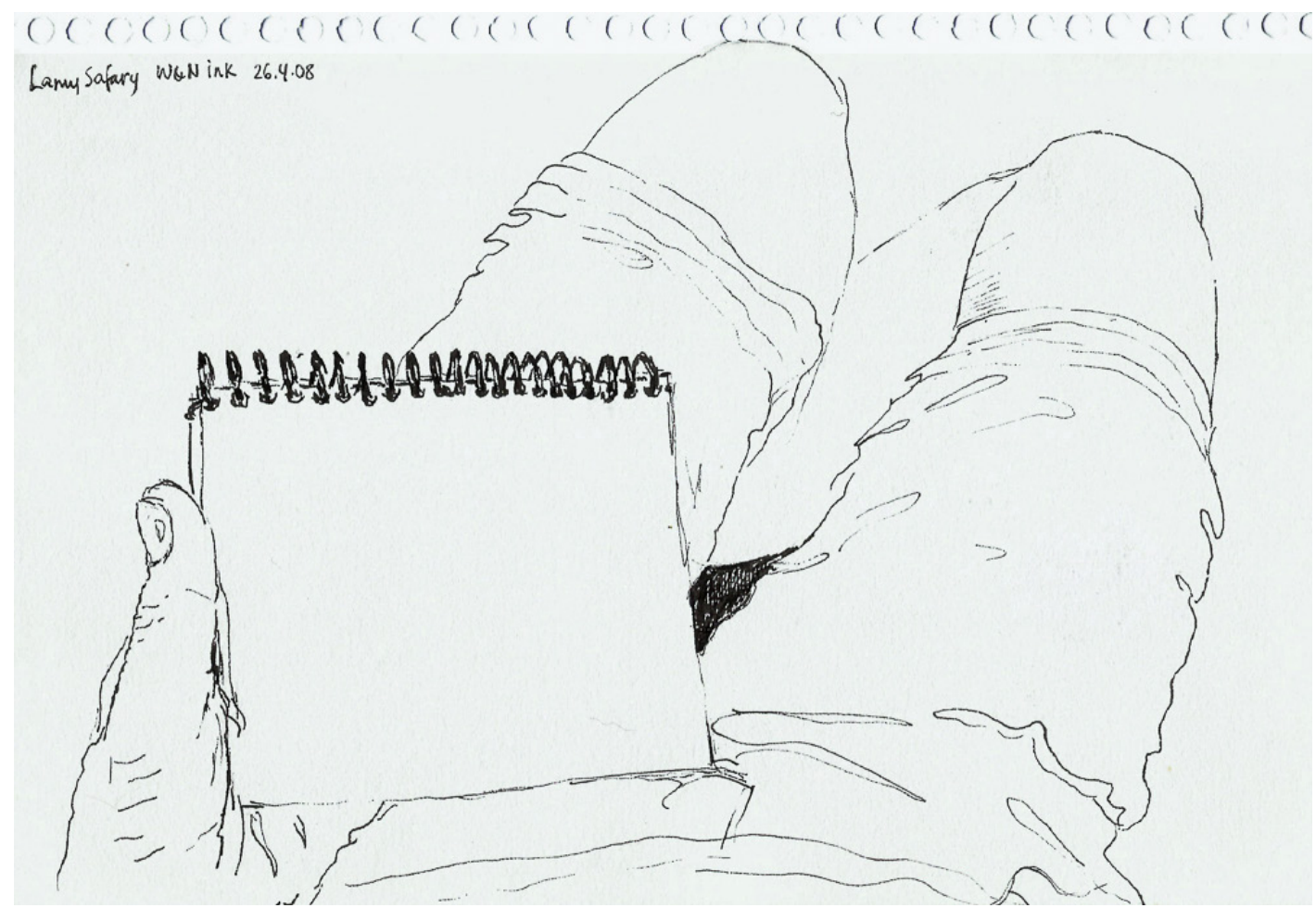

"First, drawing was nothing, then it became freedom."

É com muita alegria que escrevo esta introdução ao dossiê Antropologia e Desenho da revista Cadernos de Arte e Antropologia em 2016. Constatar o crescimento da área é revigorante. Passaram-se apenas cinco anos desde que o tema se tornou parte da minha vida como pesquisadora e, coincidentemente, ganhou maior visibilidade na literatura antropológica internacional. Parece pouco, mas o que vimos nesse intervalo de 2011 até o presente foi muito: a bibliografia

1 Karina Kuschnir é professora do Departamento de Antropologia Cultural do Instituto de Filosofia e Ciências Sociais da Universidade Federal do Rio de Janeiro, Brasil. Contato: karinakuschnir@gmail.com. 
diminuta e tangencial multiplicou-se e adensou-se, como tão bem ilustram os autores deste volume e suas referências. Já abordei recentemente algumas dessas obras e suas consequências práticas para uma renovação do trabalho etnográfico (Kuschnir 2016a). Nesta introdução, faço um comentário panorâmico da área, acreditando que minha própria aproximação do assunto ilustra algumas de suas características atuais. Busco estabelecer a relação do tema com o universo de valores antimodernizantes, assim como sintetizar algumas das discussões abordadas por seus autores-chave.

Eu estaria mentindo se dissesse que foi na própria antropologia que encontrei inspiração para escrever meu primeiro plano de pesquisa sobre desenho e etnografia. $\mathrm{Na}$ época, tudo que eu conhecia de antropologia visual girava em torno das câmeras de fotografar e de filmar, enquanto na antropologia da arte e do grafismo, o foco era na produção indígena. Durante a escrita do projeto, não existiam ainda dois livros que se tornaram referências na área, I swear I saw this (de Michael Taussig) e Being Alive (de Tim Ingold), ambos publicados em algum momento desse mesmo ano de 2011. E, por incompetência e falta de tempo para um bom levantamento bibliográfico, escaparam-me as Histórias Etíopes, de Manuel João Ramos (2010 [2000]), e os artigos fundamentais de Afonso e Ramos (2004), Ramos (2004), Hendrickson (2008, 2010), Leal (2008), entre tantos outros dispersos.

A ideia de que o pesquisador também pudesse desenhar (e, portanto, conhecer o mundo por meio desse processo) me veio de outro lugar. Eu ia escrever "da arte", mas essa não é bem a palavra correta. Nos anos 2000, surgem nas livrarias e na internet, em diferentes lugares do mundo, autores dedicados à produção de desenhos de observação que não se identificam como artistas. São sketchers - ou, como diz a boa tradução portuguesa, "desenhadores" - pessoas que desenham para registrar sua vida, suas viagens, suas memórias. Não almejam as galerias de arte nem a venda de seus trabalhos, tampouco a redação de teses acadêmicas: desenham (e escrevem) em cadernos. Desse período, surge uma renovação da paisagem gráfica através de plataformas online de compartilhamento de imagens e textos tais como Yahoo Groups (grupo Every Day Matters, fundado por Danny Gregory, em 2004, inspirado em seu livro com o mesmo nome, de 2003), Blogger (O Desenhador do Quotidiano, de Eduardo Salavisa, criado em 2006, pouco antes da publicação do livro Diário de Viagem, de 2008, organizado pelo autor) e Flickr (onde surgiu o grupo Urban Sketchers, em 2007, de Gabi Campanhario). Em pouco tempo, milhares de pessoas estavam participando desses espaços, lendo os livros que os inspiraram e desenhando em cadernos - eu inclusive.

Em 2011, aconteceu o segundo encontro internacional dos Urban Sketchers (USK), em Lisboa, Portugal. Ao participar desse evento (como aluna), conheci mais de perto vários autores cujos projetos esfumaçavam as fronteiras entre desenho e produção de conhecimento. Fiquei fascinada em mergulhar nessa conversa que me pareceu sinceramente interessada no diálogo interdisciplinar. Ali, por exemplo, ouvi a palestra de Ruth Rosengarten (2012), primeira autora da antropologia que conheci diretamente fazendo uma apresentação sobre o tema "antropologia e desenho", onde chegara por via dos historiadores do cotidiano e dos desenhadores urbanos.

Uma semana depois desse evento, de volta ao Brasil, me vi diante de uma oportunidade: faltava um mês para enviar o pedido de renovação do meu projeto como bolsista-pesquisadora junto ao $\mathrm{CNPq}$ (principal órgão de fomento à ciência e tecnologia do Brasil). Após vinte anos publicando na área da antropologia da política, onde fiz minha carreira, resolvi apostar na aventura de propor uma investigação sobre desenho e antropologia urbana. E não escrevo aventura 
como recurso retórico. Eu estava certa de que perderia a bolsa e de que não convenceria meus pares avaliadores de que aquele tema fazia sentido. Minha sensação era de tatear no escuro. Onde estavam as referências e a teoria antropológica? Eu mal suspeitava. Felizmente, me deram crédito (Kuschnir 2011).

O resto é história. O diálogo entre antropologia e desenho está cada vez mais produtivo. Em 2016, foram organizados pelos menos dois dossiês em revistas acadêmicas sobre o tema - além deste, da Cadernos de Arte e Antropologia, o assunto foi central na edição de agosto da Visual Ethnography (Kuschnir 2016a). Passamos também a encontrar artigos sobre desenho em periódicos de referência como Journal of the Royal Anthropological Institute (Grimshaw \& Ravetz 2015) e Visual Anthropology Review (Geismar 2014). Na pós-graduação, estamos começando a colher os resultados no campo das dissertações de mestrado e teses de doutorado (como mostram vários artigos deste volume).

Mas do que falam os autores quando abordam antropologicamente o desenho, ou melhor, quando abordam "desenhativamente" a antropologia? Perdoem o neologismo, mas foi justamente por essa última perspectiva que, do meu ponto de vista, se fortaleceu a ideia de que registros gráficos e antropologia têm grande potencial de contribuição mútua. Foi por gostar de desenhos e da experiência de desenhar que antropólogos e antropólogas trouxeram essa prática para dentro de suas reflexões profissionais, e não ao contrário.

Como sabemos, ao longo do século XX, o desenho perdeu seu protagonismo para os equipamentos de produção de imagens como a câmera fotográfica e filmadora. $\mathrm{O}$ aprendizado da técnica vai desaparecendo dos currículos escolares (ao menos na tradição ocidental) e seus profissionais deixam de figurar como membros indispensáveis de equipes de pesquisa, passando a ocupar áreas e nichos específicos, seja em núcleos de ilustração científica, seja em artes, arquitetura e design. Mesmo nesses campos, o meio digital ocupou grande parte da produção do conhecimento visual gráfico.

Nas ciências sociais, a presença do desenho ficou praticamente restrita às pesquisas onde $o$ universo de interesse é, ele próprio, o produtor das imagens, como na pintura corporal, na confecção de padronagens, marcas e "quimeras" visuais nos mais diversos suportes (Severi e Lagrou 2013). Mais do que um esquecimento, Leal (2008) aponta para a necessidade da antropologia de se afastar de uma prática (de desenhar) tão fortemente associada ao empreendimento colecionista, folclórico, pouco preparada para enfrentar questões abstratas (cosmológicas, estruturais, subjetivas) que ganham tanta centralidade na disciplina ao longo do século, especialmente no pós-guerra. Não me refiro aqui às dimensões do desenho na forma de diagramas, redes, árvores de parentesco e mapas que, justamente dando conta de abstrações e sínteses, estão presentes nas obras antropológicas como se fossem entidades objetivas. A tal ponto isso ocorre que se tornam invisíveis como marcas gráficas feitas por sujeitos específicos. Surgem como "dados", cujas formas e autorias não são problematizadas ou sequer identificadas nos créditos da imagem. Não seriam também desenhos? (Gell 1999)

Essas são apenas algumas das pistas que nos levam a considerar a relação da antropologia com o desenho não como um campo isolado, mas como parte do panorama filosófico mais amplo da disciplina, que se movimenta na complexa tripartição de oposições e complementações entre iluminismo, romantismo e nominalismo/empiricismo, tal como delineados por Duarte (2012). A redescoberta da prática de desenho etnográfico - agora como parte de um projeto 
subjetivo do investigador, uma das chaves do momento atual - a meu ver caminha junto com a proposta de se reinventar a produção antropológica pelos autores do horizonte pós-moderno.

Ao se contrapor a uma suposta configuração moderna dos saberes sociais (fria, materialista, racional), a antropologia teria como missão "voltar à vida" (para citar o projeto de Ingold 2011), resgatando valores como "sensibilidade, subjetividade, criatividade, espontaneidade, espírito, fluxo, experiência, pulsão, vida, totalidade, singularidade - com complexas articulações internas e ênfases conjunturais variadas" (Duarte 2012: 425). Para Duarte, ao contrário do que defendem muitos dos autores do cenário, esse movimento não constituiria uma inovação ungida pela "epistemologia xamânica" (o outro etnológico por excelência), mas uma reinvenção de muitas ideias que navegam nas correntes românticas (ou neorromânticas) e nominalistas da própria história do pensamento ocidental (idem, p. 432).

Um aspecto fundamental da análise de Duarte é mostrar que, ao contrário do que ocorreu no campo das ciências sociais, a partir do século XVIII, os ideais do empirismo romântico do ocidente continuaram férteis no mundo da arte, "toda ela dedicada (...) a esse estado alternativo, criativo e sensível" (idem, p. 422). Para o autor, a antropologia-pós vai em busca de "novas fórmulas vitais", mais "sensíveis", mais "fluidas", e cada vez mais próximas dos domínios da arte, exatamente a região onde, segundo Lévi-Strauss, os ocidentais ainda protegem e deixam "florescer" o seu "pensamento selvagem" (idem, p. 428; e Lévi-Strauss, apud Duarte, 2012: 440).

Faz diferença, portanto, perceber que é pelo viés da experiência artística que o desenho se reaproxima do fazer antropológico nesse início do século XXI, e não ao contrário. A abordagem é pela via de uma arte fortemente inspirada nos valores românticos, descolada de molduras mercadológicas ou profissionalizantes. O caderno como suporte para o registro gráfico - em suas várias acepções de diário de viagem, caderno de campo, sketchbook, bloco de notas e de esboços visuais - é o objeto que, a meu ver, simboliza a ponte entre o mundo do desenho e o da etnografia. O caderno está intimamente relacionado com seu portador, ambos (autor e objeto) imersos numa viagem em busca da observação e da vivência em um cotidiano estrangeiro. Diários gráficos como os de Debret, Delacroix, Picasso, Klee, Le Corbusier, são frequentemente citados como inspiração para o desenho de observação que valoriza o "testemunho" de um autor mergulhado não apenas numa paisagem (natural ou urbana) mas numa "experiência" local, em modos de vida (Salavisa, 2008; Kuschnir, 2011, 2012). Como afirma, Rosengarten (2012), inspirada em Certeau, pode-se perder a visão do todo, mas busca-se uma exploração "corporal" e "sensitiva" dos espaços.

A crítica de Duarte (2012) ao que ele denomina de "horizonte pós" não é pela sua maior ou menor adesão ao universo de valores românticos, mas pela atitude de seus autores em se apresentar como inventores de uma "nova" antropologia, num movimento que beira a automistificação. Com exceção de Ingold $(2011,2013)$ - claramente imbuído do papel de profeta da linha que trará a "vida" de volta à antropologia -, entendo que grande parte dos antropólogos que está, atualmente, explorando as possibilidades do desenho etnográfico não se enquadra nesse tipo de crítica. Ao contrário, afinadas em diferentes graus com a busca por uma investigação mais sensível, subjetiva, criativa e vivida, as publicações da área também parecem reconhecer sua dívida com a tradição malinowskiana de trabalho de campo, especialmente em suas fortes influências românticas, e não somente as empiricistas e positivistas, conforme lembra Duarte (2012), seguindo a argumentação de Strenski (1982). Para este último, o tom neorromântico de Argonautas do pacifico ocidental é crucial para entendermos a obra, como podemos constatar em 
um dos trechos finais do livro, onde Malinowski descreve, num único parágrafo, seu objetivo de buscar a cosmologia (Weltanschaunng) nativa para compreender seu "sopro de vida", aquilo pelo qual se "vive e respira", seu "zest of life"; sendo a etnografia uma busca por vários "tipos de vida", a "vida e o mundo de vários ângulos” (Malinowski 1922:517, apud Strenski 1982:766).

Os ideais de um fazer antropológico que valoriza o trabalho de campo intenso e imersivo (a la Malinowski) e conectado às dimensões da subjetividade, da criatividade, do fluxo e da experiência se alinham fortemente com as noções de John Berger, autor-chave do campo da arte, que fertiliza muitos dos trabalhos antropológicos na área (e deste volume). Em uma formulação famosa, Berger reafirma a centralidade do sujeito e da sua singularidade na produção do desenho de observação: uma árvore desenhada não é uma árvore, mas uma "árvore desenhada por alguém” (2005:71). É do reconhecimento desse self, e não somente daquilo que está fora dele, que o investigador vivencia (e registra) o mundo à sua volta. Ou seja, o sentido de um desenho é indissociável da biografia, do olhar e da imaginação de seu autor, bem como das condições em que foi produzido, tema central na discussão contemporânea sobre a autoria etnográfica (idem, p.3). Para Berger, o que está em jogo não é tanto o resultado - a linha desenhada -, mas o processo vivido: aquilo que o desenhador passa a enxergar e conhecer a partir da experiência de traçar o papel. O tempo é alongado pela imersão do observador numa relação com quem (ou o quê) observa (idem, p.70). O argumento é que esse diálogo produz uma temporalidade estendida que se contraporia ao tempo "congelado" pela fotografia ou ao ritmo mecânico do filme, contraste que será muitas vezes reforçado pelos adeptos da contribuição do desenho para a antropologia, embora contestado de forma contundente por Grimshaw \& Ravetz (2015), em resposta a Ingold (2013).

Como nos aspectos destacados acima, o diálogo de antropólogos com a perspectiva de Berger (2005) sobre o desenho se afina com o discurso antimodernizante, mas não se trata de um campo homogêneo. Embora se inspirem na obra do autor, Ingold (2011, 2013) e Taussig (2011), por exemplo, levam suas lições para caminhos bem diferentes. Para o primeiro, o conceito de desenho opera quase sempre como uma ação de valor universal, desprovida de sujeito, tempo e espaço. Suas propriedades intrínsecas são as de "sempre abrir uma passagem", de ser "anti-totalizante", afeita ao "holismo" e ao "processo", e não à "estrutura" (Ingold, 2011:179). Em Taussig, as potencialidades do desenho apontadas por Berger precisam ser enfrentadas na lógica etnográfica. Não por acaso, o primeiro capítulo de seu livro sobre o tema começa com uma frase que apresenta a relação indissociável de uma imagem desenhada com seu autor, seu foco de observação (nesse caso, duas pessoas), seu suporte, local e data: "This is a drawing in my notebook of some people I saw lying down at the entrance to a freeway tunnel in Medellin in July 2006.” (Taussig 2011:i).

Não cabe aqui realizar uma revisão da bibliografia recente sobre antropologia e desenho. A tarefa já foi muito bem-sucedida no excelente artigo de Aina Azevedo, neste volume, onde a autora faz um ótimo levantamento da literatura sobre o tema, em especial da história do desenho etnográfico e suas implicações contemporâneas. Sua discussão densa de autores atuais como Geismar (2014), Ballard (2013), Taussig (2011) e Ramos (2004, 2010 e outros) nos mostra o potencial do desenho não só para representar algo graficamente, mas para revelar modos de ver, de se comunicar e de registrar utilizados por antropólogos em campo. Destaque-se também a boa recuperação da argumentação gráfica em Gell (1975), das experiências etnográficas com desenhos como as de Colloredo-Mansfeld (2011) e Causey (2012), do debate com a antropologia visual contemporânea mais ampla, a partir de Grimsham \& Ravetz (2015) e a da já 
mencionada distinção téorica vs. etnográfica na abordagem do tema por Ingold (2011 e outros) e Taussig (2011). É muito bem colocado pela autora a mistura de "empolgação e dúvida" que acompanha o ressurgimento do desenho na prática antropológica, destacando com humor seu lugar de "novidade velha". Azevedo, sem dúvida, preenche a lacuna de contar essa história, apontando com otimismo para a riqueza da cena atual da antropologia desenhada.

Também é muito bem-vinda a reflexão de Philip Cabau sobre a especificidade do desenho etnográfico, explorada com criatividade e cuidado, por um autor que olha simultaneamente de perto e de longe para a área, nos oferecendo importantes insights e uma agenda de formação. Por comparação às demais ferramentas visuais, para Cabau - inspirado em Berger (2005), Valéry (2002) e outros -, o ato de desenhar teria o papel de prolongar a atenção no campo, testemunhando não só aquilo que se observa mas a experiência do observador, tornando-se, ele próprio, um ato-performance de integração do etnógrafo ao meio estudado. Sua melhor prática seria, paradoxalmente, aquela onde os resultados se saem "mal", escapando das armadilhas da plasticidade, do realismo e das figurações previamente codificadas (como enfatizado por Taussig 2011). Do ponto de vista do autor, o ensino do desenho seria benéfico na formação da "caixa de ferramentas" da antropologia desde que focado na ideia de uma "percepção negociada", um "processo de olhar" voltado para a captura de ideias internas mais do que externas. O que realmente importa não é a aparência que surge dos traçados, mas os problemas e questões suscitados pelo processo dessa experiência visual e etnográfica.

Já o fascinante artigo de Christine Escallier integra este volume trazendo o que a antropologia sabe fazer melhor: pesquisa de campo densa em diálogo com fontes e reflexões teóricas. Recuperando a tradição da história das técnicas, que marca o estudo das práticas marítimas, a autora discute em profundidade o potencial dos variados tipos de imagens etnográficas. Suas experiências no campo mostram que fotografias e desenhos não têm propriedades intrínsecas, mas sim significados construídos segundo as diversas circunstâncias de produção e recepção de seus conteúdos. É especialmente rica sua discussão sobre autoria e memória: filmes, iconografia histórica, fotografias de variadas origens e desenhos da própria etnógrafa e de seus interlocutores participam de um debate sobre foco e potencial narrativo por meio de imagens. A partir de problemas específicos do seu campo, Escallier apresenta várias comparações contundentes, como nos desenhos de mapas, na descrição de práticas pesqueiras e no uso de materiais como objetos sociais. Num exemplo sobre pesca com redes, vemos croquis e fotografias, lado-a-lado, demonstrando que a cooperação desenho-foto é essencial para entendermos sociologicamente tanto a composição técnica dos materiais quanto os movimentos corporais gerados nos processos de sua utilização. Difícil não concordar com o argumento da autora de que as visualidades - em seus múltiplos formatos - devem ser objetos de análise em si mesmas, indo além do papel de testemunhar, registrar, observar (Mauss, 1967). O trabalho criativo de Escallier demonstra que os diferentes tipos de imagens se complementam, enriquecendo nossa compreensão das relações sociais e tornando visíveis os silêncios e invisibilidades do universo etnografado.

Num bonito e instigante relato analítico e visual, Inês Belo Gomes nos conta sua passagem do mundo da arte para o da antropologia, e sua posterior redescoberta do desenho à luz da experiência de campo. Refletindo sobre esse, por vezes, doloroso processo, a autora formula uma questão nada óbvia: "O que é que faz com que o desenho seja etnográfico?" A pergunta atravessa o texto, trazendo à tona temas já apontados aqui como os da reciprocidade do "gesto etnográfico" (Pina Cabral 2007) e da busca por narrativas antropológicas menos objetificantes, na contramão da pulsão "voyeurista” de produção de imagens, como alerta Campos (2011:256), 
citado pela autora. O desenho, afirma Gomes, não é etnográfico; o desenho "torna-se" etnográfico a partir dos paradigmas de seu autor/autora, comprometido com modos de ver, interpretar e entender o mundo pelo recorte da antropologia. Saímos dessa leitura reconciliados com nossas falhas e acertos, acrescidos pelas imagens sugestivas e pela narrativa generosa de Gomes conosco e consigo mesma.

Generosidade e empatia também são palavras pertinentes para apresentar o artigo de Thiago Calil, uma narrativa visual sobre momentos vividos pelo pesquisador na cracolândia em São Paulo. Os desenhos, de variadas autorias, são impactantes e poéticos, afinados com a fragilidade das circunstâncias e a necessidade de anonimato dos envolvidos. $\mathrm{Na}$ opção pela expressividade emotiva (das imagens), os artistas exploraram uma dimensão do desenho que amplia sua distância frente ao registro gráfico (ou fotográfico) documental. Mesmo nas imagens iniciais, onde existe algo de representacional, os traços trazem vazios ao redor do grupo estigmatizado, tornando-o ora frágil, frente às edificações ao redor, ora forte e autônomo, a exemplo da inteireza do homem que não quer "depender de ninguém". Os casos dramáticos se sucedem, como na situação de quase morte presenciada ou na história do rapaz que arrasta sua perna ferida como se ela - a ferida - "fizesse parte dele" para sempre. A opção do autor por juntar esse gênero de desenhos com longos trechos do diário de campo potencializa a transmissão dos dramas e reflexões vividos na investigação e contribui para complexificar o conceito de narrativa etnográfica.

Este volume fica lindamente completo com o ensaio visual de Fernando Camargo, onde temos a oportunidade de folhear um diário de campo inteiro, da capa à contracapa, desenvolvido pelo autor em sua pesquisa de mestrado sobre a Rua do Porto, em Piracicaba, cidade do interior paulistano. A delicada mistura de panoramas fotográficos, desenhos e colagens guia o nosso olhar para uma cartografia da vida local, animada por pessoas, espaços, objetos e animais. O destaque para o universo dos peixes, dos pescadores e de seus instrumentos de trabalho dialoga com o artigo de Escallier e nos dá a ver o processo de aprendizado do próprio pesquisador a respeito dos modos de sobrevivência e lazer em torno das águas do rio Piracicaba.

Creio que seja útil terminar apontando alguns dos temas transversais aos vários autores que têm escrito e desenhado nesse campo. De forma muito sintética, eu diria que, ao trazer o desenho para dentro da antropologia, problematizam-se duas dimensões centrais da área: a experiência etnográfica e a produção de narrativas a partir dela. Da primeira, se desdobram questões como as do diálogo entre as subjetividades de investigadores e interlocutores, da busca de horizontalidade entre esses universos, da evocação de memórias, da produção de trocas e colaboração, mas sobretudo do projeto de viver uma experiência de campo num tempo alongado, de modo sensível, focada em captar o momento e consciente das próprias limitações desse empreendimento. Da segunda, fruto dessa consciência, se enfrentam os problemas da representação e fabricação de uma alteridade sistematizada, objetificada, pela linearidade da voz antropológica e seus "jogos hermenêuticos" (Ramos 2010: 25). Contra essas armadilhas, os textos e as imagens artesanais evocariam fragmentos das múltiplas dimensões do processo vivido, dando a ver as possibilidades e impossibilidades da produção (e divulgação) do conhecimento etnográfico e antropológico.

Todavia, até que ponto podemos afirmar que a produção de desenhos (sejam de observação, imaginação, memória; sejam dos investigadores ou interlocutores) impacta tanto na antropologia? Nos perguntarmos sobre isso é importante para não cairmos num processo de reificação e encantamento da ideia de "desenhar", como se estivéssemos diante do novo graal da antropo- 
logia. Em nome do desenho, jogaríamos a câmera e a filmadora, junto com toda a reflexão da antropologia visual (ou não) na vala das ideias "frias" e ultrapassadas? Não, não contem comigo para acender essa fogueira.

Como desenhadora e apaixonada por desenhos, acho mais do que saudável a valorização dessa prática que é, por si mesma, um espaço de prazer, liberdade, registro e reflexão, com muitas especificidades. Por isso, escolhi como epígrafe para esta introdução a frase de um interlocutor do artista Nelson Paciência a respeito da sua experiência de aprender a desenhar numa prisão de segurança máxima (Kuschnir, 2016b). Para a imagem que abre o artigo, optei por um desenho num caderno meu antigo, tendo como objeto o próprio caderno segurado por mim. Estou ali, diante da primeira página em branco, a sugerir um processo em aberto, como um convite. Vamos desenhar para somar, multiplicar. Como demonstram os vários autores desse volume, etnografia com fotos, filmes, desenhos, cadernos, sujeitos, lugares, línguas, valores, lutas, diálogos, experiências: todas essas dimensões importam.

\section{RefERÊnCias Bibliográficas}

Afonso, Ana Isabel, Manuel João Ramos. 2004. "New Graphics for Old Stories: Representation of local memories through drawings". Pp. 66-83 in Working Images: Visual Research and Representation in Ethnography, edited by A. I. Afonso, L. Kurti e S. Pink. London: Routledge.

Ballard, Chris. 2013. "The Return of the Past: On Drawing and Dialogical History”. The Asia Pacific Journal of Anthropology, 14:2, 136-148.

Berger, John. 2005. Berger on Drawing. Jim Savage (ed.) Aghabullogue: Occasional Press.

Campos, Ricardo. 2011. "Imagens e Tecnologias Visuais em Pesquisa Visual: tendências e desafios”. Análise Social, XLVI (199): 237- 259.

Causey, Andrew. 2012. "Drawing flies: artwork in the field." Critical Arts, 26 (2), pp. 162-174.

Colloredo-Mansfeld, Rudi.2011, "Space, line and story in the invention of an Andean aesthetic". Journal of Material Culture, 16 (1): 3-23.

Duarte, Luiz Fernando D. 2012. "O paradoxo de Bergson: diferença e holismo na antropologia do Ocidente." Mana, 18(3): 417-448. Disponível em <https://dx.doi.org/10.1590/S010493132012000300001>.

Geismar, Haidy. 2014. "Drawing it Out". Visual Anthropological Review, 30 (2): 96-113. Disponível em <http://onlinelibrary.wiley.com/doi/10.1111/var.12041/full>.

Gell, Alfred. 1975. Metamorphosis of the Cassowaries. Used Society, Language and Ritual. London: The Athlone Press. 1999. The art of anthropology - Essays and Diagrams. Edited by E. Hirsch. Londres: The Athlone Press.

Gregory, Danny. 2003. Everyday Matters: A Memoir. New York: Hyperion.

Grimshaw, Ann, Amanda Ravetz. 2015. "Drawing with a camera? Ethnographic film and transformative anthropology." Journal of the Royal Anthropological Institute, vol. 21, issue 2: 255-275. Disponível em <http://onlinelibrary.wiley.com/doi/10.1111/1467-9655.12161/ abstract>.

Hendrikson, Carol. 2008. "Visual Field Notes: Drawing Insights in the Yucatan". Visual Anthropology Review, 24 (2): 117-132. Disponível em <http://onlinelibrary.wiley.com/ doi/10.1111/j.1548-7458.2008.00009.x/abstract >. 
.2010. “Ethno Graphics: Keeping Visual Field Notes in Vietnam”. Expedition, Vol 52, n 1:

31-39. Disponível em <http://www.penn.museum/documents/ publications/expedition/ PDFs/52-1/Ethno-Graphics.pdf>.

Ingold, Tim. 2011. Being Alive - Essays on movement, knowledge and description. London and

New York: Routledge.

2013. Making. Anthropology, archeology, art and architecture. London and New York: Routledge.

Kuschnir, Karina. 2011. "Drawing the city - a proposal for an ethnographic study in Rio de Janeiro." Vibrant - Virtual Brazilian Anthropology, 8(2): 609-642. Disponível em <http:// goo.g1/66GqES>.

.2012. “Desenhando Cidades”. Sociologia E Antropologia. Vol. 02.04: 295-314. Disponível em <http://revistappgsa.ifcs.ufrj.br/wp-content/uploads/2015/05/14-ano2-v2n4_ registro_karina-kuschnir.pdf>.

. 2014. "Ensinando antropólogos a desenhar: uma experiência didática e de pesquisa". Cadernos de Arte e Antropologia 3(2): 23-46. Disponível em <https://cadernosaa.revues. org $/ 506$ ?lang=en>.

. 2016a. "Ethnographic Drawing: Eleven benefits of using a sketchbook for fieldwork." Visual Ethnography. v.5:105-138. Disponível em <http://www.vejournal.org/index.php/ vejournal/article/view/92>.

.2016b. “A liberdade de desenhar." Karina Kuschnir: desenhos, textos e coisas. Disponível em <https://karinakuschnir.wordpress.com/2016/08/18/nelsonpaciencia/ >.

Mauss, Marcel. 1967. Manuel d'ethnographie. Paris: Payot.

Pina Cabral, João. 2007. "Aromas de Urze e de Lama: reflexões sobre o Gesto Etnográfico". Etnográfica, 11 (1): 191-212.

Leal, João. 2008. “Retratos do povo: etnografia portuguesa e imagem.” Pp. 117-145 in O visual e o quotidiano, editado por J. Machado Pais, C. Carvalho e N. M. Gusmão. Lisboa: Imprensa de Ciências Sociais.

Ramos, Manuel João. 2004. "Drawing the lines - The limitation of intercultural ekphrasis." Pp. 147-156 in Working Images: Visual Research and Representation in Ethnography, edited by A.

I. Afonso, L. Kurti e S. Pink. London: Routledge. 2009. Traços de Viagem. Lisboa: Bertrand Editora. 2010. Histórias Etíopes, Diário de viagem. Lisboa: Tinta da China.

Rosengarten, Ruth. 2012. "Passing by, stopping, walking on: urban sketching in context." Pp. 24-51 in Urban Sketchers em Lisboa. Lisboa: Quimera. (Edição Bilíngüe)

Salavisa, Eduardo. 2008. Diários de Viagem - desenhos do quotidiano, edited by E. Salavisa. Lisboa: Quimera Editores.

Severi, Carlo e Lagrou, Els. (orgs.) 2013. Quimeras em diálogo: grafismo e figuração nas artes indígenas. Rio de Janeiro: 7 Letras.

Strenski, Ivan. 1982. "Malinowski: second positivism, second romanticism”. Man, 17(4):266271.

Taussig, Michael. 2011. I swear I saw this. Drawings in fieldwork notebooks, namely my own. Chicago and London: The University of Chicago Press.

Valéry, Paul. 2002. Degas Danse Dessin. Paris: Gallimard. [Em português: 2012. Degas Dança Desenho. São Paulo: Cosac Naify.] 